\title{
DOS ASPECTOS HISTÓRICOS AOS TENSIONAMENTOS DE INCLUSÃO DO POVO PRETO NO CONTEXTO CONTEMPORÂNEO
}

\author{
DE LOS ASPECTOS HISTÓRICOS A LA INCLUSIÓN TENCIONAMENTE DEL \\ PUEBLO NEGRO EN EL CONTEXTO CONTEMPORTÁNEO
}

\author{
FROM HISTORICAL ASPECTS TO THE INTENTIONS OF INCLUSION OF BLACK \\ PEOPLE IN THE CONTEMPORARY CONTEXT
}

\author{
Leandro Costa VIEIRA ${ }^{1}$ \\ Eladio SEBÁSTIAN HEREDERO ${ }^{2}$
}

\begin{abstract}
RESUMO: Este ensaio teórico buscou traçar um recorte no espaço/tempo do século XX em que o movimento social do povo preto enfrenta uma revolução em busca de respeito e a minimização dos processos de racismo, discriminação e preconceito que subjugam estes como marginais e, por assim ser discriminados constantemente. Apontamos momentos da história da sociedade brasileira e suas adequações organizativas numa referência eurocêntrica, em normas e, a militância negra, com suas idiossincrasias como essencial para o reconhecimento de que as diferenças existem e precisam impreterivelmente ser debatidas. Finalizamos o ensaio com uma análise crítica/reflexiva acerca das políticas sociais dos governos mais recentes buscando e reconhecimento da inclusão como peça-chave de empoderamento, protagonismo e compreensão do lugar do povo preto na história A educação como um dos atos da inclusão é pautada no texto de maneira que atravessa o processo reflexivo/crítico e de militância na ordem social do mundo contemporâneo.
\end{abstract}

PALAVRAS-CHAVE: Inclusão. Movimento social. Marginalização. Discriminação. Preconceito.

RESUMEN: Este ensayo trata de hacer un recorte espacio temporal del siglo XX en el que el movimiento social del pueblo negro hizo una revolución en busca del respeto y de la minimización de los procesos de racismo, discriminación y preconcepto que colocaban a estos como marginales y, por eso, ser discriminados constantemente. Señalamos momentos históricos en la sociedad brasileña, a veces adecuados organizativamente según los criterios europeos, en normas para la militancia negra, con sus características como esenciales para el reconocimiento de que las diferencias existen y precisan ser debatidas y repensadas urgentemente. Finalizamos el ensayo con una análisis crítico-reflexivo sobre las políticas sociales de los gobiernos más recientes buscando el reconocimiento de la inclusión como pieza clave de empoderamiento, protagonismo y comprensioln del lugar del pueblo negro en la historia. La educación es una de las acciones de la inclusión que está reflejada en el texto

\footnotetext{
${ }^{1}$ Universidade Federal de Mato Grosso do Sul (UFMS), Campo Grande - MS - Brasil. Doutorando no Programa de Pós-Graduação em Educação. ORCID: https://orcid.org/0000-0002-6800-8020. E-mail: leandro.vieira@ufms.br

${ }^{2}$ Universidade Federal de Mato Grosso do Sul (UFMS), Campo Grande - MS - Brasil. Professor Visitante, atua no Programa de Pós-Graduação em Educação. Professor Aposentado da Universidad de Alcalá - Espanha. ORCID: https://orcid.org/0000-0003-0293-4395. E-mail: eladio.sebastian@gmail.com
} 
de forma transversal en este proceso de reflexión y de militancia en el orden social del mundo contemporáneo.

PALABRAS CLAVE: Inclusión. Movimiento social. Marginalización. Discriminación. Preconcepto.

ABSTRACT: This theoretical essay aimed at outlining some space/time in the 20th century in which the black people's social movement faced a revolution in the search for respect and mitigation of racism, discrimination and prejudice processes since they suppressed these individuals, considered them delinquents and, consequently, discriminated them regularly. We pointed out some moments of the history of the Brazilian society and their organizational adequacy in Eurocentric reference and norms, besides black militancy, with its idiosyncrasies, as essential factors to acknowledge differences that need to be debated. We ended the essay by carrying out a critical/reflexive analysis of the latest government's social policies in the search for inclusion as a key of empowerment, protagonism and comprehension of the black people's place in History. Education, as one of the inclusion acts, is shown in the text as an element that intertwines the reflexive/critical process and militancy in the social order in the contemporary world.

KEYWORDS: Inclusion. Social movement. Marginalization. Discrimination. Prejudice.

\section{Introdução}

A sociedade mundial num todo tem como condição a busca pela liberdade e o direito à vida, consolidando assim, perspectivas que potencializem o protagonismo e a livre condição de escolhas de mulheres e homens e de todas as nações. O Brasil tem proporcionado desde a sua redemocratização, a busca por direitos civis entre todos os seus cidadãos, amparados pela Constituição Federal de 1988, bem como os direitos previstos na Declaração dos Direitos Humanos. Reza em seu Artigo 1 que "Todos os seres humanos nascem livres e iguais em dignidade e direitos. São dotados de razão e consciência e devem agir em relação uns aos outros com espírito de fraternidade" (ONU, 1948, p. 3).

Faz-se entender que para ser livre desde seu nascimento, e por toda vida, buscando assim iguais direitos, foram necessárias lutas e leis, tal como o acordo internacional, firmado durante a conferência de 1948, pelos países membros das Nações Unidas em acordo com a liberdade, igualdade e dignidade humana.

O presente escrito irá tratar o modo como a inclusão é, no presente cotidiano de mulheres e homens de pele escura, um processo em construção; dos processos discriminatórios que irão interferir diretamente no direito à educação, os direitos sociais, e em definitiva no tratamento desde uma perspectiva inclusiva.

RPGE- Revista on line de Política e Gestão Educacional, Araraquara, v. 25, n. 2, p. 1207-1221, maio/ago. 2021. e-ISSN: 1519-9029 
A educação como direito de todos e dever do Estado brasileiro surge no marco de discussões e defesa desta no limiar dos anos de 1980, com o processo de redemocratização do Brasil e a promulgação da Constituição Federal vigente. Nos anos de 1990, houveram inúmeras transformações na educação, surgem desde marcos históricos e social de diferenças e discriminações (das mais diversas).

Rememorando ainda o começo do século XX, o direito a aprender, de estudar, seria prioritariamente para os filhos da classe burguesa, considerando-se assim, um processo formativo para dar conta de status sociais reconhecidos e bem-quistos pelo seu núcleo de relações. As reformas educativas dos anos de 1930 irão ocorrer com intuito muito óbvio que se volta ao mercado, se volta à formação de homens e mulheres para a execução manufatureira da fábrica.

Vai ser apenas depois da Lei de Diretrizes e Base (LDB) 9.394 de 1996 e as posteriores regulamentações que haverá uma busca mais intensa por igualdade, com tentativas de se concretizar a perspectiva da inclusão de todos e todas num espaço fundamental da educação brasileira, embora sem uma específica menção para os pretos ou pardos, bem como outros grupos sociais que por hora, ainda não se encontram contemplados com propostas de igualdade e equidade educativa e social (BRASIL, 1996).

\section{O povo preto do começo do século: direitos e deveres negados por uma sociedade discriminatória e racista}

Devido ao processo mercadológico do povo negro, do continente africano para as Américas, em especial, para o Brasil durante três séculos, o percentual de pessoas pretas e pardas torna-se maior do que das autodeclaradas brancas. $\mathrm{O}$ 'preteamento' ${ }^{3}$, da população brasileira corrobora para um processo estrutural de racismo, discriminação e preconceito.

$\mathrm{Na}$ catastrófica história do final da escravização do povo preto brasileiro, também marca o começo da miserabilidade deste grupo social, considerando as condições que eram encontradas naquele espaço/tempo de direitos negados, de um processo de "libertação", acompanhado também da saída das tutelas dos homens brancos, donos destes pretos, sem a garantia de emprego no campo, na fábrica, tendo assim o começo de ocupação de periferias, o que adiante tornar-se-ia o que conhecemos como margem social.

Segundo Silvio Almeida:

${ }^{3} \mathrm{O}$ preteamento se caracteriza diretamente como adjetivo para que um contingente de sujeitos, mulheres e homens da sociedade brasileira se identificam como preta, negra, que tem a pele escura. 
A consequência de práticas de discriminação direta e indireta ao longo do tempo leva a estratificação social, um fenômeno intergeracional, em que o percurso de vida de todos os membros de um grupo social - o que inclui as chances de ascensão social, de reconhecimento e de sustento material - é afetado (ALMEIDA, 2020, p. 33, grifos do autor).

Ao levar a pensar sobre as consequências da discriminação direta ou indireta, Almeida (2020) transpõe as circunstâncias dos atos discriminatórios, de preconceito e racismo que se afloram com força durante o século XX, principalmente nas suas primeiras décadas. Haverá aqui um emaranhado de obstáculos que levarão estas mulheres e homens do final dos anos de 1800 e do começo dos 1900 a tecerem lutas ou sucumbirem-se aos ditames do sistema social que marginalizaria as pessoas pretas, por sua cor de pele e pela história de escravização sofrida por este povo.

Gislene Santos (2002) estrutura um apanhado histórico sobre o movimento abolicionista, liderado por José Bonifácio, ainda que de forma arbitrária, e que buscava um processo que proporcionasse que todo cidadão tivesse direitos e deveres, pertencentes ao Estado brasileiro (SANTOS 2002), ou seja, a base desta 'luta' de Bonifácio, se caracteriza pelos aspectos liberais do mundo moderno, concretizando-se assim, um modelo de liberalismo nacional.

O princípio do liberalismo adotado por várias nações europeias pelo qual José Bonifácio prescreve que haja um Estado forte e cidadão plenos em direitos e deveres. Os escravos não são cidadãos, portanto, contrariam a adoção de uma Constituição liberal. Entretanto, antes de apontar os caminhos para a construção do liberalismo nacional, Bonifácio percorre outras veredas demonstrando o porquê de a escravidão ser tão nociva a este mesmo liberalismo. O que, consequentemente, já se constitui numa proposta política (SANTOS, 2002, p. 67).

"O ideal do republicanismo brasileiro não emancipou a população negra - o que instiga o debate sobre que tipo de republicanismo é esse que não garantiu liberdade e igualdade entre os grupos étnicos da formação social brasileira" (SANTOS, 2009, p. 33). Ainda em destaque em Gevanilda Santos, (2009), é importante entender que:

O republicanismo ao gosto da elite nacional instituiu o direito civil mais formal que real, sem considerar a resistência e o protesto negro. Já foi dito que o povo assistiu "bestificado" à proclamação da República. Tal expressão é muito difundida nos livros didáticos e traz um alerta à falta de participação popular nos feitos históricos nacionais (SANTOS, 2009, p. 33-34).

Desde o final dos anos de 1920 e toda a década de 1930 com a ascensão de Vargas frente ao governo do Brasil, houveram inúmeras reformas, seja nas conquistas de direitos 
trabalhistas, seja nas condições educacionais, que se faziam necessárias para que o Brasil fosse incluído no sistema mundial de industrialização deste período entre guerras.

A escola pública elementar será condicionada às populações de pessoas mais pobres, no sentido de ensinar as primeiras letras e as operações básicas da matemática, como sentidos significativos no trabalho a ser executado na fábrica. Fonseca (2009), destaca em síntese a Lei 19.482/1930, popularmente conhecida como lei dos $2 / 3$. O que veio a garantir que $2 / 3$ das vagas de emprego fossem destinadas aos trabalhadores brasileiros natos.

A partir desta garantia, o contingente de pessoas pretas integrando o mercado de trabalho iria ser um pouco mais amplo, proporcionando desta forma que a população preta se organizasse, assim como os movimentos negros, a exemplo disso tem-se a Frente Negra Brasileira, que buscou criar postos de trabalho e qualificação profissional social desta população.

Tudo isso fez que reivindicações pela integração do negro na sociedade republicana repercutissem em jornais e boletins de diversas entidades negras que denunciavam o racismo e a marginalização criminosa existente no país, particularmente no mercado de trabalho (FONSECA, 2009, p. 88).

Os espaços educativos seriam outros lugares em que o preconceito e o racismo seriam presentes, porém, por se tratar de uma organização hierárquica verticalizada, muitas destas ações não seriam reveladas de maneira objetiva e clara, porém fariam com que as crianças da época refletissem apenas na fase adulta, anos depois, as ações racistas que sofreram no universo escolar.

A característica da escola tradicional reverberava em uma concepção única de aprendizagem. Maneira esta que necessariamente tem na figura do professor como transmissor de conhecimento e o estudante como receptor, como se este não tivesse qualquer conhecimento prévio, ou estes eram desconsiderados no contexto educacional. Segundo Leão (1999, p. 190):

A abordagem tradicional do ensino parte do pressuposto de que a inteligência é uma faculdade que torna o homem capaz de armazenar informações, das mais simples às mais complexas. Nessa perspectiva, é preciso decompor a realidade a ser estudada com o objetivo de simplificar o patrimônio de conhecimento a ser transmitido ao aluno que, por sua vez, deve armazenar tão somente os resultados do processo. Desse modo, na escola tradicional o conhecimento humano possui um caráter cumulativo, que deve ser adquirido pelo indivíduo pela transmissão dos conhecimentos a ser realizada na instituição escolar. 
Fazendo uma reflexão acerca da abordagem tradicional de ensino, entender-se-á as condições que não incluiriam as pessoas pretas do processo de aprendizagem. Não se tratava de que pessoas pretas eram menos inteligentes ou com menores capacidades de aprendizagem do que pessoas brancas. Porém, se o que mais importava era o resultado da transmissão de tal conhecimento, como salienta Leão (1999), as crianças pretas por não terem a necessária atenção no processo de aprendizagem, também não tinham a garantia de sorver de todos os elementos necessários para identificar os códigos ensinados.

Houve uma escola que limitou os que tinham e os que não tinham direito ao aprendizado, os que podiam ou não frequentar a escola e, por consequência, seriam incluídos ou excluídos dos processos de aprendizagem. Far-se-ia desta forma, ideias de um modelo de educação 'ideal', para época, porém, que deixaria de fora do prosseguir de estudos a maior parte da população com direito à escolarização, por serem socialmente excluídos em diversos sentidos, fatores econômicos, culturais, étnicos, de raça e crença da escola como 'tábua de salvação'.

\section{Os privilégios que não chegam aos pretos}

O empobrecimento econômico, social e cultural do povo preto reverbera com as condições de exclusão social, de direitos negados em diferentes setores. A falta de escolarização, de alfabetização, como elementares no construto do conhecimento dos direitos sociais de diferentes sujeitos interpela diretamente no modo como este se apresenta em sociedade. Desde as escolhas de seus representantes políticos, desde o emprego a ser exercido por estes, bem como todas as condições econômicas e sociais que representam um perfil, ainda que estereotipado, destes sujeitos.

Os corpos negros são estereotipados como corpos de desejos, sentidos plurais da objetificação deste corpo. Houve um contexto de abolição, no entanto, não houve a ruptura necessária para que estes corpos fossem libertos de desejos não saciados, não houve a ruptura de ver estes corpos como força de trabalho, como julgamento da ignorância e de buscar justificar diferenças biológicas em que se posicionava a inferioridade negra diante da superioridade branca.

Nessa trajetória de inferiorização do preto e do preteamento da sociedade brasileira, foi necessário a busca de justificativas para o branqueamento social. Ser branco é sinônimo de superioridade - Está certo, ou fora incutido em nossa insana consciência de que isso é verdadeiro e real? - A busca por compreender o que leva a uma defesa do branqueamento 
social como necessária ao desenvolvimento pleno de um grupo, de uma cidade ou de uma nação é elementar quando se analisa essa ideia de branqueamento com ponto de partida no processo de colonização europeia em diferentes partes do mundo.

Ao final do século XVIII, ainda haviam buscas de justificar a diferença biológica entre brancos, negros e indígenas, por parte dos que não lutavam pela abolição. No entanto já havia sido comprovado a partir das "[...] investigações biológicas do século XVIII, apesar de todas as ressalvas, provaram, definitivamente, a humanidade dos negros africanos. Sendo homens poderiam e deveriam lutar pela conquista de sua liberdade" (SANTOS, 2009, p. 76).

Quando se enfatiza aqui os privilégios que não são focados às pessoas pretas, não é significado de vitimismo ou algo de mesma nuance. Os privilégios estão presentes e são bastante explícitos, seja no ambiente de trabalho, no tratamento dado às pessoas com pele escura desde à infância. A respeito disso, encontraremos em dados divulgados pelo IPEA (2019) que a média de anos estudados por pessoas pretas em 1995 com 60 anos ou mais era em média de 1,4 anos de escolarização, enquanto pessoas brancas era de 3,6 anos de formação básica.

Quando se faz a análise deste tempo de escolarização em 1995 pela faixa etária de pessoas com 60 anos ou mais que passaram pela escola em tempo regular entre as décadas de 1930, anteriores e posteriores, entende-se que o disparate de tempo de escolarização de brancos e negros nascidos no começo do século XX, já que têm um diferencial de 2,2 anos de escolarização. Compreende-se ainda, que o Brasil se caracteriza por uma política interna que não fomentava o direito à escolarização de pessoas pobres e, que essa parcela da população, que seria de maior percentual, permanecia em média 2,6 anos nos bancos escolares.

O direito à educação é pauta de discussão, visto que saber é sinônimo de emancipação e de protagonismo. Quando a população mais pobre se caracteriza por não ter acesso aos saberes escolares, que as levam a conhecer seus direitos, esta população fica fadada à manipulação e submetida aos ditames dos que historicamente estão no poder.

Se saber é poder, existe ainda hoje, pleno século XXI, a ideia de que o saber irá interferir diretamente no modo como a sociedade se comporta. Se estabelecem, dessa forma, condições e concepções que defendem o direito à educação, que determinam o tempo de permanência das habilidades de aprendizagem, porém são estabelecidos estes critérios a partir da necessidade de operários para determinadas frentes de trabalho e, que isso irá interferir no provento e nas condições do exercício profissional. Quanto menor a instrução, maior a marginalização do trabalho, caracterizando-se assim, a subalternização, exclusão e indiferença. 
Com a condição de não ter acesso a níveis mais elevados da educação, a população preta, terá como reflexo disso no sistema de emprego e renda, medidos estes pelo sistema previdenciário público do INSS (Instituto Nacional de Seguridade Social) e pelo IBGE (Instituto Brasileiro de Geografia e Estatística). Paixão e Theodoro (2020) realizaram estudos acerca da previdência e da seguridade social da população preta brasileira, identificando esta, desde a Constituição Federal de 1988, seguindo assim, por todas as transformações e reformas ocorridas entre os anos de 1990 até a década de 2010.

Nas perspectivas identificadas pelos autores, é fato que a população preta vive um estado de pobreza e miserabilidade proporcionalmente maior que a população branca. Além disso a população preta em média ganha $\mathrm{R} \$ 1.100,00$ a menos que os brancos. Identificou-se ainda que $46,5 \%$ da população em idade de mercado de trabalho, encontra-se exercendo atividades profissionais informalmente e que $78,5 \%$ da população de pretos recebe os menores salários (PAIXÃO; THEODORO, 2020).

Os aspectos citados acima enaltecem a condição que se estrutura de que as pessoas pretas e pardas, ainda hoje, com todas as políticas sociais contra todo tipo de discriminação e preconceito, sofre com o problema do racismo, que se alicerçou e se estrutura nas múltiplas faces sociais do Brasil.

Quando se analisa a condição econômica e de possibilidades trabalhistas da população preta, encontra-se as circunstâncias que forjam o modo como a educação irá interpelar diretamente nas vidas destas pessoas, por meio dos processos não includentes, anteriores a Constituição de 1988 e demais providências (BRASIL, 1988).

\section{O processo de escolarização do povo preto}

$\mathrm{Na}$ trajetória de miscigenação ou mistura que garantiu o entendimento de que o povo preto se caracteriza por um percentual maior do que de brancos - sem nem tocar na condição do indígena no Brasil - tem-se então que pensar: que práticas são postas em exercício cotidiano e constante na formação educativa de meninas e meninos que se identificam como pretos ou pardos desde suas raízes familiares e, que muito não se identificam com o espaço/tempo do que é ensinado na escola?

Ao pensar em práticas educativas e inclusão educacional, percebe-se a necessidade de expor e proporcionar elementos formativos que garantam aos públicos mais diversos a identificação, a discussão e o entendimento das diferenças. Não seria completo corroborar com a ideia de que a cultura e a história do provo preto é suficiente para elencar os aspectos 
que influenciam a inclusão de pretos e pardos no contexto educativo enquanto práticas de inclusão educacional.

Maria Mantoan (2015, p. 22), destaca que:

[...] a escola não pode continuar ignorando o que acontece ao seu redor, nem anulando e marginalizando as diferenças nos processos pelos quais forma e instrui os alunos. E muito menos desconhecer que aprender implica ser capaz de dar significado a objetos, fatos, fenômenos, à vida. Expressar, dos mais variados modos, o que sabemos implica representar o mundo com base em nossas origens, em nossos valores e sentimentos.

Em acordo com o que a autora expressa na passagem acima, faz-se importante pensar sobre "dar significado a objetos, fatos, fenômenos, à vida" (idem). Como é possível significar algo que não atravessa de forma inebriante o ato formativo de saberes adquiridos desde o que a escola potencializa como conteúdo validado e enquanto saberes necessários para formação de um sujeito? - Faz-se necessário retomar à ideia de que para a realização de uma formação integral e composta de condições que se alicerçam em significados e sentidos de tal formação, torna-se importante transformar a escola em sua totalidade, o que não é sinônimo da derrubada da escola atual, mas de reconsiderar práticas ainda hoje exercidas de forma hierárquica e, em alguns casos, opressora.

Para Paulo Freire e Nogueira (1993, p. 40-41):

Quando a prática é tomada como curiosidade, então essa prática vai tomar horizontes de possibilidade. As pessoas então fazem de seus discursos um panorama do que é possível fazer. Não se limitam apenas àquilo que deve ser feito. As pessoas descobrem com a prática as suas possibilidades. Mesmo dentro dos limites analisados, as pessoas organizam esforços para viabilizar o que está sendo difícil de ser feito. Penso que esse processo amadurece os intelectuais e os grupos populares. Penso que nesse processo as pessoas não se limitam a discutir sobre conteúdos, mas as pessoas discutem sobre as dimensões e os momentos da prática.

Os autores irão provocar a pensar a prática educativa em um viés caleidoscópico, percebendo a prática que vai além de conteúdos ou da reorganização curricular em si, mas uma reorganização da ideia de tal prática, exercida esta 'com um' determinado grupo e não 'para um' determinado grupo. Quando se pensa o exercício da prática 'com', é possível aí, entender mais sobre como exercer de forma orgânica e com amplo horizonte formativo, a liberdade e o protagonismo dos saberes compartilhados.

Se concebeu um modo de se ensinar, como se todos fossem providos dos mesmos insites cerebrais para codificar o que por hora está presente como conteúdo obrigatório de sala de aula. Se tratar a inclusão como o guarda-chuvas de diálogo com as diferenças, 
naturalmente, precisa-se conceber a educação escolar de forma múltipla, flexível e transformadora, que sai de sua zona de conforto.

É impossível entender ou buscar um diálogo referente a práticas educativas inclusivas se estas não entendem o papel fundamental de saberes outros que necessitam estar na escola como ato de pertença de meninos e meninas, para relacionar o que reconhecem enquanto conteúdo global, ou seja, aquele igual em todo e qualquer espaço educativo e o conteúdo significativo, que engloba em sua explicação lógica aspectos do cotidiano vivo destes sujeitos.

Se conceber-se uma escola inclusiva que vislumbre uma construção coletiva de saberes, esta precisa ser de escutas, precisa ser de constantes transformações. As transformações curriculares necessariamente prescindem do atravessamento dos saberes, da transversalidade das áreas, para que na complexidade seja possível corroborar com o esperado sentido plural de educação inclusiva. Ainda Mantoan (2015, p. 23) destaca que:

O pensamento subdividido em áreas específicas é uma grande barreira para os que pretendem, como nós, inovar a escola. Nesse sentido, é imprescindível questionar o modelo que rege o ensino, dos primeiros passos de nossa formação escolar aos níveis educacionais mais graduados. Toda trajetória escolar precisa ser repensada, considerando-se os efeitos cada vez mais nefastos das hiperespecializações dos saberes, que dificulta a articulação de uns com os outros e nos proporciona igualmente uma visão do essencial e do global.

Ao se deparar com discussões acerca da inclusão educacional, existirá um grupo de estudiosos que naturalmente abrirá discussões para os aspectos da educação especial, das deficiências, enfim, salientando o que tem sido defendido no processo histórico da inclusão educacional. Ao deslumbrar uma investigação que trata de práticas educativas inclusivas em que o cerne é o público de pretos e pardos, talvez o que se ouvirá enquanto crítica preconcebida é a concepção de diversidade e dos estudos das relações étnico-raciais. No entanto, o vislumbrar é entender como o público de pessoas pretas e pardas se faz presente nas práticas educativas respeitando a pertença e o construto social, cultural, intelectual, artístico, político e econômico do povo preto para a sociedade brasileira.

Se o povo preto promoveu mudanças que se fazem presentes no cotidiano social do brasileiro, ainda que historicamente marginalizado e invisibilizado, por onde poder-se-ia começar a promover práticas de inclusão de pretos/pardos no cotidiano escolar, sem enaltecer datas comemorativas, tais quais treze de maio e vinte de novembro? - O protagonismo deste grupo social em discussão promove transformações e enlaces que forjam uma sociedade menos desigual. 
É necessário constituir práticas inclusivas que corroborem com ações que disseminem a busca por maior aproximação de igualdade entre os sujeitos. É urgente entender que a militância por respeito e diálogo da negritude, como algo que ultrapasse os espaços de movimentos sociais, dos grupos organizados, mas que seja episteme que protagoniza a constituição de memória, de trabalho, ação e formação da sociedade brasileira. Para tanto, é preciso que a escola eduque as novas gerações para que estas sejam conscientes de que as distinções raciais foram concepções construídas ainda no mundo antigo e se perpetuam ainda hoje.

As décadas que se seguiriam ainda na primeira metade do século $\mathrm{XX}$ seriam de um começo de organização de movimentos negro. Haveria assim a construção de concepções e estereótipos da imagem dos pretos, os quais não serão detalhados, mas alguns destes citados: sujeitos negros, considerados preguiçosos; considerados perigosos e ameaçadores; estereotipias de sujeitos feios, que teriam mau-cheiro por consequências da pele escura; considerados descapacitados de desenvolvimento de saberes e aprendizagens presentes na escola.

\section{A militância por inclusão social no Brasil}

O Brasil perpassa o século XX com múltiplas construções no que se refere à inclusão social da população no todo, com retrocessos e avanços nas dinâmicas que proporcionariam que as desigualdades sociais se afunilassem, no entanto, não houve na realidade essa construção, pois os processos de exclusão social em alguns sentidos se ampliaram, construindo-se assim, um abismo entre opressores e oprimidos.

Segundo Petrônio Domingues (2007), a organização de um movimento negro se deu ainda no começo do século XX, com a criação de inúmeros grupos e agremiações negras, como forma de se organizarem enquanto sujeitos de direito, buscando estabelecer dentro destes grupos, condições para resistência ao processo de discriminação vivenciado por aquelas pessoas de 'pele escura'. O autor afirma que:

Na primeira metade do século XX, a FNB foi a mais importante entidade negra do país. Com "delegações" - espécie de filiais - e grupos homônimos em diversos estados (Rio de Janeiro, Minas Gerais, Espírito Santo, Pernambuco, Rio Grande do Sul e Bahia), arregimentou milhares de "pessoas de cor", conseguindo converter o Movimento Negro Brasileiro em movimento de massa. Pelas estimativas de um de seus dirigentes, a FNB chegou a superar os 20 mil associados (DOMINGUES, 2007, p. 106). 
O período da ditadura de Vargas proporcionou que o movimento negro tivesse várias influências que não necessariamente potencializariam os ideários de um movimento mais popular e de inclusão. No entanto, o envolvimento deste no âmbito político corroborou com as ideias provindas dos movimentos políticos e mesmo de regimes totalitários espelhados em Mussolini ou mesmo em Hitler (DOMINGUES, 2007).

Já o período da ditadura militar, foi um tempo entre o esvaziamento do movimento negro e a reorganização deste. Desde esta reorganização, o processo de torturas e os volumosos processos de assassinatos de sujeitos civis, nos porões da ditadura, levam também, ao aquecimento e reorganização do movimento. Cria-se então o MNU (Movimento Negro Unificado) que dará vazão a outras lutas e buscas da condição preta na sociedade.

Ao se discorrer acerca das condições, lutas e conquistas do movimento, corrobora-se com a ideia de que o processo de inclusão dar-se-á primeiramente na condição de (re)conhecimento do ser preto brasileiro.

[...] no contexto de rearticulação do movimento negro, aconteceu uma reunião em São Paulo, no dia 18 de junho de 1978, com diversos grupos e entidades negras (CECAN, Grupo Afro-Latino América, Câmara do Comércio Afro-Brasileiro, Jornal Abertura, Jornal Capoeira e Grupo de Atletas e Grupo de Artistas Negros). Nesta reunião, decidiu-se criar o Movimento Unificado Contra a Discriminação Racial (MUCDR), e a primeira atividade da nova organização foi um ato público em repúdio à discriminação racial sofrida por quatro jovens no Clube de Regatas Tietê e em protesto à morte de Robson Silveira da Luz, trabalhador e pai de família negro, torturado até a morte no $44^{\circ}$ Distrito de Guainases. $\mathrm{O}$ ato público foi realizado no dia 7 de julho de 1978, nas escadarias do Teatro Municipal em São Paulo, reunindo cerca de 2 mil pessoas, e "considerado pelo MUCDR como o maior avanço político realizado pelo negro na luta contra o racismo (DOMINGUES, 2007, p. 113, grifos do autor).

$\mathrm{Na}$ fase mais recente do movimento negro, alguns aspectos foram importantes na defesa de uma identidade e a busca por diminuição dos processos discriminatórios contra o povo preto. Domingues, 2007 destaca alguns destes como necessários e relevantes para o histórico do movimento. Numa conjuntura internacional o movimento em busca de direitos civis que comungam com uma concepção de afrocentrismo (DOMINGUES, 2007), estrutura nos Estados Unidos uma militância de descolonização, viés este que seria adotado e necessário de ser compreendido em outras partes do mundo.

O Brasil passa a caracterizar como termo de autoidentificação oficial a nomenclatura "negro", "afrodescendente" ou "afro-brasileiro" (DOMINGUES, 2007). Na militância do movimento, a busca por inclusão se dá por meio dos direitos sociais de todo cidadão brasileiro, concebido através do processo democrático e buscando discutir o que fora 
construído como "democracia racial", que se derivada de um mundo eurocêntrico, branco e heteronormativo, configurar-se-á um processo concebido nos moldes do racismo estrutural e do racismo institucional, que apregoa concepções engessadas da figura e do papel do preto em sociedade.

Os caminhos da inclusão social focando-se ao povo preto é um caminho distante de se percorrer, no sentido de entender como a sociedade tem se adequado a compreender as diferenças enraizadas historicamente por este núcleo social. É preciso reconhecer a história destes homens e destas mulheres acerca de suas narrativas, de sua autobiografia humana, desde suas origens ao que se constitui hoje, sem cercear o direito desta trajetória ser oficialmente reconhecida e tida como elemento de formação de meninas e meninos desde sua tenra infância até a fase adulta.

\section{A modo de considerações, que não finais}

Entende-se que uma organização social interfere diretamente no modo como a sociedade irá vislumbrar os encaminhamentos necessários à diminuição de paradoxos entre os diferentes grupos é, na medida do possível, o caminho aberto para o processo de inclusão e diálogo com a diversidade.

Se houve um século mergulhados em políticas contraditórias que corroboram de um lado com a busca por direitos humanos que convergem com a igualdade entre todos, tem-se de outro lado um processo militante em busca de uma referência única de modelo social. Concepções e exercícios contínuos de sustentação deste modo de perceber e vivenciar o mundo, corrobora assim com os aspectos que não proporcionam a inclusão devida e desejada.

As políticas públicas brasileiras no processo de reabertura política, buscam firmar mudanças exponenciais no âmbito social, porém, ainda em passos pequenos e que driblam caminhos pedregosos. O que se almeja dizer com isso, é que as políticas sociais nascem com uma proposta que considere todo e qualquer cidadão independente de toda e qualquer especificidade sua. A Carta Magma de 1988 busca a defesa de que todos são iguais perante a lei, assim como determinantes que estabeleceriam os direitos cidadãos, desde o nascimento até a morte, fica claro que se trata de todos independente da sua cor de pele.

Partilha-se assim, de uma legislação que em sua utopia e no desejo do porvir, vislumbra a diminuição dos paradoxos e desrespeitos de toda e qualquer natureza, no entanto, nas práticas cotidianas, talvez haja ainda aquém do que está regido e tensionado desde a 
Constituição de 1988, porém o marco normativo chave esta aí e vale ser lembrado a todo momento como forma de garantir a tão desejada igualdade.

Quando mergulha-se na busca por um entendimento em saber: onde está na prática cotidiana as vivências e experiências de inclusão? Notoriamente, nosso encontro será com uma idealização institucionalizada por leis; contradita por diferentes governanças e, renegada por parcelas da população ao não se identificarem por ou com grupos minoritários.

A condição preta no Brasil não foge de estereótipos e conjunções arbitrárias provindas de diversos espaços e culturas, por assim dizer, criou-se o 'mito' da branquidade social, como o aceito e bem recebido. No entanto, como já diria o compositor... "A carne mais barata do mercado, 'foi' a carne negra" (SOARES, 2002). Para sair de esse impasse não apenas serve a legislação, é mais importante a consciência coletiva e a construção dos conceitos de cidadania em passos decididos em prol do respeito coletivo às pessoas.

Para que se concretize o desenvolvimento educativo de maneira pertinente e significativa, se faz necessário estabelecer vínculos que caracterizem a identidade do povo preto, afrodescendente ou afro-brasileiro, uma parte da inclusão passa pelo reconhecimento da diferença e como esta pode potencializar um crescimento social em suas diversas nuances e características, enriquecendo assim, a cultura do povo, reconhecendo sua concepção e nunca negando a existência desta. Todos os passos dados, e relatados aqui, são importantes, mas como projeto de sociedade igualitária e inclusiva devemos seguir trabalhando neste processo que não tem um fim, porém tem tantos desdobramentos como faces e para tanto infinitas ações.

AGRADECIMENTOS: O presente trabalho foi realizado com apoio da Universidade Federal de Mato Grosso do Sul - UFMS/MEC - Brasil.

\section{REFERÊNCIAS}

A carne. Intérprete: Elza Soares. Compositor: Seu Jorge, Marcelo Yuka, Wilson Cappellette. In: DO CÓCCIX até o pescoço. Intérprete: Elza Soares. São Paulo: Tratore, 2002. 1 CD, faixa 6 (4min).

ALMEIDA, S. Racismo estrutural. São Paulo, SP: Editora Jandaíra, 2020.

BRASIL. Constituição (1988). Constituição da República Federativa do Brasil. Brasília, DF: Senado, 1988. 
BRASIL. Lei n. 9.394, de 20 de dezembro de 1996. Lei de Diretrizes e Bases da Educação Nacional. Diário Oficial da União: Seção 1, Brasília, DF, n. 248, p. 27833, 23 dez. 1996. PL $1258 / 1988$

DOMINGUES, P. Movimento negro brasileiro: alguns apontamentos históricos. Tempo, v. 12, n. 23, p. 100-122, 2007.

FONSECA, D. Políticas e ações afirmativas. São Paulo, SP: Selo Negro, 2009.

FREIRE, P.; NOGUEIRA, A. Que fazer: teoria e prática em educação popular. 4. ed. Petrópolis, RJ: Vozes, 1993.

IPEA. Instituto de Pesquisa Econômica Aplicada. 2019. Disponível em: https://www.ipea.gov.br/portal/. Acesso em: 10 jan. 2021.

LEÃO, D. Paradigmas contemporâneos de educação: Escola tradicional e escola construtivista. Cadernos de pesquisa, São Paulo (SP), n 107, p. 187-206, 1999.

MANTOAN, M. Inclusão escolar: o que é? por quê? como fazer? São Paulo, SP: Summus, 2015.

ONU. Organização das Nações Unidas. Declaração Universal dos Direitos Humanos. Paris, 1948. Disponível em: http://www.onu-brasil.org.br/documentos/. Acesso em: 10 maio 2020.

PAIXÃO, M.; THEODORO, M. ... para depois dividir: notas sobre Reforma Previdenciária e assimetrias raciais no Brasil. Em Pauta, Rio de Janeiro (RJ), v. 18, n. 45, p. 130-147, 2020

SANTOS, G. A invenção do "ser negro": um percurso das ideias que naturalizam a inferioridade dos negros. São Paulo, SP: Educ/Fapesp; Rio de Janeiro, RJ: Pallas, 2002.

SANTOS, G. Relações raciais e desigualdade no Brasil. São Paulo, SP: Selo Negro, 2009.

\section{Como referenciar este artigo}

VIEIRA, L. C.; SEBÁSTIAN HEREDERO, E. Dos aspectos históricos aos tencionamentos de inclusão do povo preto no contexto contemporâneo. Revista on line de Política e Gestão Educacional, Araraquara, v. 25, n. 2, p. 1207-1221, maio/ago. 2021. e-ISSN:1519-9029. DOI:

https://doi.org/10.22633/rpge.v25i2.15013

Submetido em: 08/04/2021

Aprovado em: 06/05/2021

Publicado em: 01/08/2021 